\title{
COVID-19: opportunity arises from a world health crisis
}

\author{
Peter L. Bonate ${ }^{1}$ \\ Published online: 26 March 2020 \\ (C) Springer Science+Business Media, LLC, part of Springer Nature 2020
}

Coronavirus needs no introduction. It's all anyone talks about these days and rightfully so. These are crazy times, scary times. As I write this, I am sitting at a makeshift desk on the dining room table at my house, wearing sweatpants with one of my dogs at my side, because I've been told to work from home until further notice. Both of my children are home from college, taking the remainder of their classes online, and being told to not plan on returning to school until the fall semester. Like I said, crazy times, and uncertain times as well. No one knows exactly what the next 6 months will be like. How many people will be infected? How many will die? How long will it take for things to go back to normal?

People want answers, they demand answers, but there are few at the moment-at least not definitive answers. This situation is entirely new. Every day brings new estimates and new events. People are willing to listen to any expert that provides an answer with a sense of assurance and confidence. These experts are seen on television 24-h a day; they are reported in the newspapers. Every expert has an answer, but no one knows for sure. Let's be clearmany of them are making nothing more than educated guesses. With this crisis there is an opportunity, there is an opportunity for modeling and simulation to provide not the answers, but an estimate of the answers, maybe better estimates of the answers. We can move beyond experts with educated guesses and provide answers based on sound scientific modeling and simulation (M\&S).

Every day there are new estimates of what the death toll will be, about how bad it will get. As a modeler, I am thrilled to see that the news is now starting to include $M \& S$ in their stories. The New York Times reported how network modeling was being used to map the spread of the virus [1]. The Washington Post used an online agent-based simulation to illustrate the spread of the virus in a

Peter L. Bonate

peter.bonate@astellas.com

Astellas, 1 Astellas Way, Northbrook, IL 60062, USA hypothetical town and how to "flatten the curve" [2]. Even medical journals that normally do not publish mathematical models are quick to publish modeling results related to coronavirus. The Lancet [3] published a study using a 4-state model (susceptible, exposed, infectious, and removed) combined with a random walk process to understand the transmission rate of the virus over time.

Scientific papers, like the Lancet paper, are generating a lot of press around their results and implications. As modelers, care needs to be taken in disseminating these results and I would like to highlight a few issues regarding their dissemination. First, model predictions themselves have errors associated with them and we need to ensure that these are reported as well. Second, the assumptions we use to build our models must always remain transparent. Lastly, we must remember who the audience is - the general public or our fellow scientists. We must always present our results with the audience in mind. The NY Times published a graph of fatality rate vs. rate of disease spreading for a variety of different viruses, trying to put into context how coronavirus compares to say SARS or chickenpox [4]. Because of the range of the fatality rate data, the authors used a log-scale without any minor tics. Without these minor tics, the average reader would conclude that the death rate was near $10 \%$, but because of the $\log$-scale, the actual value was around 2 to $3 \%$ (the true value is still being debated). The graph was not intentionally misleading, but it was also not drawn with the average reader in mind. This graph was corrected a few weeks later by the authors, along with some added text to explain what a log-scale. Errors like these decrease the credibility of the point you are trying to make and distract from what your message is.

Mathematical models are all around us, even if the average person does not realize it. They help us every day to reduce uncertainty. Should I take an umbrella because it might rain? How can I get to this new address I am unfamiliar with? What is the risk of a heart attack for someone like me? I don't want to minimize the tragedy that is happening, and will continue to happen in the near future, but coronavirus offers the modelers of the world an 
opportunity—an opportunity to reduce the uncertainty and fear of what will come, an opportunity to provide advice on how "flatten the curve" and reduce the death toll, and there are many other opportunities just waiting for an answer. If you see an opportunity, take it. Mankind may thank you.

Be well and stay healthy,

Peter L. Bonate, PhD

Editor-in-Chief

\section{References}

1. Carey B (2020) Mapping the social network of coronavirus. New York Times, 13 March 2020
2. Stevens H (2020) How outbreaks like coronavirus spread exponentially, and how to "flatten the curve". Washington Post, 14 March 2020

3. Kucharski A et al (2020) Early dynamics of transmission and control of COVID-19: a mathematical modelling study. The Lancet: Infectious Diseases, 11 March 2020

4. Sheikh K et al (2020) How bad with the coronavirus outbreak get? Here are 6 key factors. New York Times, 31 January 2020; updated 28 February 2020

Publisher's Note Springer Nature remains neutral with regard to jurisdictional claims in published maps and institutional affiliations. 